\title{
Yoga: the life changing tool to improve health of human beings
}

\author{
Parth M. Kapatel ${ }^{1 *}$
}

\section{ABSTRACT}

Yoga is a life changing tool for human beings. It is the subject of research from last few decades intended for healing purposes for modern epidemic illnesses i.e. hypertension, mental stress, obesity, coronary heart disease, diabetes, and chronic obstructive pulmonary disease. In such cases, specific research studies reported beneficial results of yoga. That means, yoga can be utilized as a nonpharmaceutical measure or counterpart to drug therapy for the treatment of these conditions/cases. In this article, research is reviewed on the effects of yoga as a tool for changing the life of human beings. In addition to this, the limbs, asana and pranayama are discussed in a proper way. Further, how that helps in solving the health problems are also discussed in this article.

\section{Keywords: Yoga, Health, life, Asana, Hypertension, Meditation}

$\mathbf{T}_{\mathrm{l}}$ he actual significance of the word yoga i.e. controlling the mental changes; communion with the universal indicates the importance it attaches to spirituals as well as mental wellbeing, extending beyond the physical wellbeing [1]. Nevertheless, from the pre-Vedic time, the practice of yoga was existing. The great Sage Patanjali combined the practical with theory thoughts of yoga into a structured arrangement before 2500 to 3000 years ago. These ideas were integrated mostly from Samkhya and Vedic philosophy [2].

Physical postures (Asanas) were in practice during the era of Sage Patanjali, however, they were not given much importance, because the focus was more on meditation and therefore few postures conducive to the practice of meditation alone were merged in their spiritual practices. If we see that as in all the Patanjali yoga sutras you don't even discover a single named asana. Sages who followed Patanjali attempted to alter yoga methods by integrating more physical elements, as focusing on movements is a little easier than just directly on the mind. Despite adding more physical components in the name of asanas, the goal remained the same - ' controlling mental alterations ' as one of the scaffolds with physical postures. Unlike other physical exercises, this is evident from the manner the asanas are practiced (slow with synchronized breathing and conscious knowledge of movements). From a conceptual point of perspective, Patanjali Yoga's eight limbs obviously signify a hierarchical (although not necessarily sequential) pattern of systematically developing consciousness from gross to subtle level [3]. Intense exercise of eight rungs of yoga results in self-realization, which is yoga's main objective. An analytical examination of the rungs and purpose of yoga

\footnotetext{
${ }^{1}$ Department of Materials Science, Sardar Patel University, Vallabh Vidyanagar, 388120, Gujarat, India. *Responding Author

Received: November 15, 2019; Revision Received: December 26, 2019; Accepted: December 30, 2019

(C) 2019, Kapatel. P.M; licensee IJIP. This is an Open Access Research distributed under the terms of the Creative Commons Attribution License (www.creativecommons.org/licenses/by/2.0), which permits unrestricted use, distribution, and reproduction in any Medium, provided the original work is properly cited.
} 
demonstrates that it is a holistic way of life that leads to a state of full physical, social, mental and spiritual well-being and harmony with nature. This contrasts with the purely financial and material development objective of modern civilization. This has given rise to social unrest and environmental destruction.

\section{METHODS}

A systematic analysis of the literature on yoga as an anxiety treatment was the technique used in this research. The following reviews were as follows: (a) published in the English language (b) Published from last two decades, (c) Include all forms of yoga as part of or as a whole, (d) Use any design for quantitative research, and (e) Measure the result of anxiety. For many ailments, yoga was used as a treatment, including hypertension, diabetes, depression, overweight, and obesity. Such articles were reviewed for the present study.

\section{Search strategy Databases:}

The Cochrane Library, PubMed and Scopus databases are included in an on-line search for databases. Also searching for yoga institutions conferences and websites and references from found papers. Terms and constraints of online search: a quick systematic search uses free-text conditions: "yoga" and "effect/pathway" and "clinical effect" "review: yoga".

\section{RESULTS}

\section{Overview about the Yoga:}

"Yoga" means union of our individual consciousness in a superconscious state known as Samadhi with the Universal Divine Consciousness. Yoga is an ancient practice of Eastern origins involving both physical postures (asanas) and methods of breathing (pranayamas). There is also a cognitive element that focuses on meditation and concentration that helps to achieve the objective of union between the self and the spiritual. While countless empirical studies have discovered a significant impact of yoga on various physical and psychological functioning aspects. Archeological proof and other texts indicate that the techniques described in the sutras of yoga were practiced as soon as 3000 BCE. Oral tradition says the date could be even sooner. Historically, yoga sutras have been passed on orally to their students by learned educators. Scholars estimate that these sutras were systematized and compiled by Patanjali, who lived sometime between 400 BCE and 200 anno domini (AD).[4] Yoga comprises, according to Patanjali, of eight steps or limbs, all of which are equally extremely important and linked as parts of the whole. These eight limbs are intended for discriminative enlightenment or self-realization [5] But the emphasis here is going to be on health advantages. The following are the eight steps or limbs of yoga [4,5]:

1. Yama: Codes of restraint, abstinences, self-regulations

2. Niyama: self-training, Observances, practices,

3. Asana: Posture of meditation

4. Pranayama: breath and prana expansion, regulation, control

5. Pratyahara: Withdrawal of the senses, bringing inward

6. Dharana: Concentration

7. Dhyana: Meditation

8. Samadhi: Deep absorption, meditation in its higher state, the state of perfected concentration 


\section{The five yamas}

The five yamas are perceived restraint codes, abstentions, self-regulations, and involve our connection with the outside globe and others. These are similarly applicable to thought, word and action. The following are the five yamas:

1. Ahimsa: nonviolence, non-harmful, 2. Satya:, honesty, 3. Asteya: nonstealings ; as far as you don't even want something that isn't yours. It also implies that we should consider borrowing from nature whatever resources are at our disposal. Using them or obtaining them for living expenses more than the minimum required to steal as they are not affordable to others. 4. Brahmacharya: walking in maximum reality consciousness, remembering the divine, practicing God's presence. It leads to celibacy as an impact or what is commonly meant by brahmacharya. 5. Aparigraha: No possessiveness, nonbonding through senses, nongreedy, nongrasping, no acquisitiveness.

\section{The five niyamas}

The five niyamas are self-training executions or procedures and cope with our secret inner world. In terms to body, senses, and mind, these are a means of self-training. The following are the five niyamas:

1. Shaucha: Body and mind cleanliness and purity. It outcomes in purification of the subtle mental essence, bringing pleasure, mastery of the senses, and self'realization capacity.

2. Santosha: Content or comfortable acceptance of what you have at the moment. It brings from within joy and happiness.

3. Tapah: A destruction of mental impurities and a subsequent mastery of the body and the mental organs of senses and actions occurs through ascesis or training of the senses.

4. Svadhyaya: self-study, holy words reflection, and scriptural study. Through this one achieves communion with the natural truth underlying it.

5. Ishvarapranidhana: Surrender to the supreme source. That helps to accomplish the state of samadhi i.e. high concentration. (Asana) Practice body-fitting postures for long periods of meditation. Any position i.e. face, neck, and chest must be in-line. Furthermore, motionless, comfortable and stable posture can be used for meditation. It is attained through relaxing attention or effort loosening to sit in such a particular posture and permitting focus to integrate with the infinite. Pranayama: Breath control practice and with the awareness of breathing (raising/decreasing) optimization techniques, pranayama practice can be done peacefully.

As previously stated, the eight yoga methods are mainly intended for self-realization. Yamas practice, however, leading to stronger internal ties would assist to promote social health. It helps to create a community in which there is self-regulation in non-harming others and in preserving honesty rather than depending on external monitoring which can definitely not always be available. Asteya and aparigraha inspire conservation of natural resources. Their approach will guarantee that all these tools are accessible to all. The five niyamas coping with our individual inner world by helping in mental health promotion through self-training methods. 
In comparison to pure financial and social growth as an aim of modern civilization, the main objective of meditation "self-realization or association of self-consciousness with the ultimate awareness" is an objective proposed to mankind.

Yama, Niyama- Asana Behavioral Level, Pranayama-Physical Level Prathyahara, DharanaMental Level Dhyana, Samadhi-Spiritual Level So, the vision of yoga was created with the intention of attaining happiness (peace) rather than wellness (health) alone as contrary to exercise.

\section{Effects of yogic practices on various health problems Depression, Stress and Anxiety}

Yoga is beneficial in both, prevention and stress-induced symptoms treatment. From the systematic review, studies show that positive results are observed after the applying yoga as a life changing tool for regular basis to the patients. In case of the obsessive-compulsive disorder, encouraging results are obtained. [6] Kirkwood $G$ et al., demonstrated in their review of "Yoga for anxiety" that after the implementation of yoga in the life of patients, moreover the beneficial effects in depression disorder was observed. It concludes as there were five randomized controlled trials, each using distinct types of yoga procedures and ranging from moderate to series in the seriousness of the situation. All studies revealed beneficial results $[7,8]$. In another research, clients receiving antidepressant drugs but only in partial remission found important decreases in depression, anger and frustration, anxiety, and neurotic signs. The research promotes yoga's ability as a supplementary depression treatment. 27 women and 10 men were joined in this specific study, of whom 17 completed the intervention and pre- and post-intervention assessment data. Results observes that moods enhanced after the yoga courses from before to after. Yoga seems to be a promising depression treatment; it is cost-effective and easy to adopt. As endorsed by findings in this research, it generates many positive mental, psychological and biological influences [9]. In one more study, 24 self-referred womans (average age of 30 to 38 years) who viewed themselves as mentally disturbed, a supervised potential non-randomized study was performed over them. Participation in one of two subsequent 3-month yoga program was provided. Yoga has been shown to decrease anxiety, stress and salivary cortisol levels $[10,11]$. Another research was performed by Smith. C. et al., in which One hundred and thirty-one participants were selected from the society in South Australia with mild to moderate stress levels. They observed that the anxiety and performance of live results enhanced over time after the 10-week intervention stress. Yoga has been discovered to be as efficient as relief in tension reduction, fear anxiety and health improvement [12]. In addition to this, one research was conducted to identify the direct cardiovascular impacts of sukha pranayama in people with hypertension. Twenty-three hypertensive participants were chosen for the research undergoing Yoga OPD at JIPMER and trained to practice sukha pranayama at a pace of 6 breaths / min for 5 minutes. This pranayama includes the inhalation and exhalation of conscious, smooth and deep breaths with similar duration. Before and instantly after the operation, the heart rate (HR) and BP were recorded. Results showed that statistical post-intervention assessment disclosed a substantial $(\mathrm{p}<.05)$ decrease in HR and a highly significant $(\mathrm{p}<.001)$ decrease in systolic pressure, blood pressure, average arterial pressure, rate-pressure product. It is found that in hypertensive patients within 5 minutes of sukha pranayama at a pace of 6 breaths / minute can decrease HR and BP. Hence, Yoga also works to recover from depression [13]. A systematic review by Jain S.C et al., mentioned that all reported yoga and HPT research revealed 39 cohort studies, 30 non-randomized, monitored tests (NRCTs), 48 randomized, controlled trials (RCTs), and 3 case reports covering a maximum of 6693 cases, varying from 1 week to 4 years. Most researches revealed that BP in 


\section{Yoga: The life changing tool to improve health of human beings}

both normotensive and hypertensive groups was efficiently lowered by yoga. These researches indicate that yoga is an efficient alternative treatment for HPT and should be included in clinical guidelines [14]. The reduced depression may be associated with modifications in brain waves and reduced levels of cortisol noticed during the postures of yoga. In one case, daily yoga exercises in one research resulted in enhanced alpha waves (indication of enhanced relaxation) and reduced cortisol [15].

\section{Overweight and Obesity}

High risk reasons for diabetes, hypertension, and ischemic heart disease are overweight and obesity. It was concluded that yoga is useful in managing obesity. Yoga asnas and pranayama training by a yoga trainer for three ongoing months, $1 \mathrm{~h}$ every day in the morning led in a reduction in body weight, body mass index (BMI), and waist hip ratio. In one study, Balaji P.A. et al., Selected 44 uncomplicated diabetic type 2 patients in the $40-55$ year age range with a 1-10 year duration of diabetes. With 22 patients in each team, they were separated into test group and control groups. The yoga specialist instructed the test group (T1 and T2) for 3 successive months, 1 hour daily in the morning. The findings indicated a significant decline in metabolic parameters, with $\mathrm{p}<0.001$ in FBS of both the T1 and T2 sub groups [16].

\section{Hypertension}

Thirty-three hypertensives patients, aged 35-65, from Government general hospital, Pondicherry were treated by medical officers. Four factors respectively, systolic and diastolic blood pressure, pulse rate and body weight were examined. The participants were divided into three groups. The exp. group-I experienced yoga methods, the physician of the said hospital got medical therapy from exp. group-II and the control group did not engage in any of the stimuli for treatment. Yoga was given $1 \mathrm{hr}$ per session per day in the morning and in the evening for a complete duration of 11 weeks. Regular yogic exercise in hypertensive patients has been observed to be effective in controlling blood pressure [17]. Hypertension is the most common non-communicable disease that causes important morbidity / mortality due to problems of the cardiac, cerebrovascular and renal system. Yoga has been discovered to have a significant antihypertensive influence, along with biofeedback, relaxation, psychotherapy and transcendental meditation [18].

Twenty-five patients were analyzed with vital hypertension. Of these, no antihypertensive drug therapy (Group A) was provided to 20 individuals; 5 other antihypertensive drugs had to be used before they were included in the research (Group B). These patients have been shown and instructed to perform "Shavasana" properly. Six months of Shavasana treatment persisted. In both the mean diastolic and systolic pressure of both groups, there was a statistically significant drop was observed. In addition, there has been a substantial decrease in antihypertensive drug amounts provided to group B patients. In 65 percent of Group A patients, only Shavasana could control blood pressure and no drug was required in them. Blood pressure in patients who stopped practicing yoga increased considerably to preShavasana concentrations. Thus, with the use of yoga (Shavasana) in hypertension therapy, antihypertensive drug requirements may be considerably reduced and may in some instances be completely dispensed with and may be a helpful aid in hypertension therapy [19]. Hence, Yoga has been beneficial to patients with mild to moderate hypertension [20]. Yoga has been performed for three months on a regular basis for 1 hour. Participants had reduced blood pressure, blood glucose, cholesterol, and triglycerides by the end of the study, and enhanced personal well-being and quality of living. Who were at risk of resting systolic and diastolic blood pressure, reduced after 20 weeks of yoga in another group [21]. 


\section{CONCLUSION}

Yoga provides important benefits in terms of improving the people's positive mental health and offering therapeutic benefits as a single or adjunct treatment for a number of physical and neuropsychiatric disorders. It probably brings permanent happiness, followed by further desires and ultimately contentment. It recovers the health from the stressful lives due to too much competition and compulsion to achieve very high targets. It also provides social equities and proper rest. It can therefore be concluded that yoga practice is important key tool to all health aspects like spiritual, physical, social, mental and at the same period that encouraging harmony with nature and helping to preserve the environment.

\section{REFERENCES}

[1] Govindaraj, R., Varambally, S., Sharma, M., \& Gangadhar, B. N. (2016). Designing and validation of a yoga-based intervention for schizophrenia. International Review of Psychiatry, 28(3), 323-326.

[2] Mohanty, J. (2008). Indian philosophy (Vol. 2). Oxford University Press, USA.

[3] Pradhan, B. (2015). Yoga: Original Concepts and History. In Yoga and Mindfulness Based Cognitive Therapy (pp. 3-36). Springer, Cham.

[4] Taneja, D. K. (2014). Yoga and health. Indian journal of community medicine: official publication of Indian Association of Preventive \& Social Medicine, 39(2), 68.

[5] Prabhavananda, S., \& Isherwood, C. Chennai: Sri Ramakrishna Math. Patanjali Yoga Sutras.

[6] Sengupta, P. (2012). Health impacts of yoga and pranayama: A state-of-the-art review. International journal of preventive medicine, 3(7), 444.

[7] Kirkwood, G., Rampes, H., Tuffrey, V., Richardson, J., \& Pilkington, K. (2005). Yoga for anxiety: a systematic review of the research evidence. British journal of sports medicine, 39(12), 884-891.

[8] Pilkington, K., Kirkwood, G., Rampes, H., \& Richardson, J. (2005). Yoga for depression: the research evidence. Journal of affective disorders, 89(1-3), 13-24.

[9] Shapiro, D., Cook, I. A., Davydov, D. M., Ottaviani, C., Leuchter, A. F., \& Abrams, M. (2007). Yoga as a complementary treatment of depression: effects of traits and moods on treatment outcome. Evidence-based complementary and alternative medicine, 4(4), 493-502.

[10] Michalsen, A., Grossman, P., Acil, A., Langhorst, J., Lüdtke, R., Esch, T., ... \& Dobos, G. (2005). Rapid stress reduction and anxiolysis among distressed women as a consequence of a three-month intensive yoga program. Medical Science Monitor, 11(12), CR555-CR561.

[11] West, J., Otte, C., Geher, K., Johnson, J., \& Mohr, D. C. (2004). Effects of Hatha yoga and African dance on perceived stress, affect, and salivary cortisol. Annals of Behavioral Medicine, 28(2), 114-118.

[12] Smith, C., Hancock, H., Blake-Mortimer, J., \& Eckert, K. (2007). A randomised comparative trial of yoga and relaxation to reduce stress and anxiety. Complementary therapies in medicine, 15(2), 77-83.

[13] Bhavanani, A. B., Sanjay, Z., \& Madanmohan. (2011). Immediate effect of sukha pranayama on cardiovascular variables in patients of hypertension. International journal of yoga therapy, 21(1), 73-76.

[14] Jain, S. C., \& Talukdar, B. (1995). Role of yoga in control of hyperglycemia in middle aged patients of non-insulin dependent diabetes mellitus. Indian Journal of Clinical Biochemistry, 10(2), 62. 
[15] Malhotra, V., Singh, S., Singh, K. P., Sharma, S. B., Madhu, S. V., Gupta, P., \& Tandon, O. P. (2004). Effects of yoga asanas and pranayama in non-insulin dependent diabetes mellitus.

[16] PA, B. (2011). Effects of yoga-pranayama practices on metabolic parameters and anthropometry in type 2 diabetes. International Multidisciplinary Research Journal.

[17] Murugesan, R., Govindarajulu, N., \& Bera, T. K. (2000). Effect of selected yogic practices on the management of hypertension. Indian Journal of Physiology and Pharmacology, 44(2), 207-210.

[18] Subramanian, H., Soudarssanane, M. B., Jayalakshmy, R., Thiruselvakumar, D., Navasakthi, D., Sahai, A., \& Saptharishi, L. G. (2011). Non-pharmacological interventions in hypertension: a community-based cross-over randomized controlled trial. Indian journal of community medicine: official publication of Indian Association of Preventive \& Social Medicine, 36(3), 191.

[19] Bhavanani, A. B., Sanjay, Z., \& Madanmohan. (2011). Immediate effect of sukha pranayama on cardiovascular variables in patients of hypertension. International journal of yoga therapy, 21(1), 73-76.

[20] Field, T. (2011). Yoga clinical research review. Complementary therapies in clinical practice, 17(1), 1-8.

[21] Cade, W. T., Reeds, D. N., Mondy, K. E., Overton, E. T., Grassino, J., Tucker, S., ... \& Yarasheski, K. E. (2010). Yoga lifestyle intervention reduces blood pressure in HIV-infected adults with cardiovascular disease risk factors. HIV medicine, 11(6), 379-388.

\section{Acknowledgements}

The author appreciates all those who participated in the study and helped to facilitate the research process.

\section{Conflict of Interest}

The authors declared no potential conflicts of interest with respect to the research, authorship, and/or publication of this article.

How to cite this article: Kapatel. P.M (2019). Yoga: the life changing tool to improve health of human beings. International Journal of Indian Psychology, 7(4), 1092-1098. DIP:18.01.127/20190704, DOI:10.25215/0704.127 